\title{
O papel do Ministério da Defesa no processo de integração e de regulação das Comunicações Militares no Brasil
}

The role of the Ministry of Defense in the process of integration and regulation of Military Communications in Brazil

\section{RESUMO}

Propósito - A finalidade deste artigo é introduzir o leitor ao contexto político e técnico em que se inserem as Comunicações Militares no Brasil, evidenciando o papel regulador e integrador exercido, atualmente, pelo Ministério da Defesa.

Metodologia/abordagem/design - Este trabalho de pesquisa faz uso predominante de abordagem expositiva e comparativa, no intuito de dotar cognitivamente o leitor a respeito do tema em destaque.

Resultados - O trabalho conclui pela necessidade de racionalização e de unificação da política nacional de Comunicações Militares, como fator condicionante à integração eficaz das Forças Armadas nas operações conjuntas.

Implicações práticas - $\mathrm{O}$ artigo destaca o benefício que a padronização de requisitos técnicos pelo Ministério da Defesa pode trazer em termos de redução de custos na aquisição e manutenção de equipamentos e sistemas de Comunicações Militares, por meio de ganhos com economias de escala, bem como em termos de ganhos de eficácia e de eficiência operacional, nas operações conjuntas das Forças Armadas.

Originalidade/relevância do texto - Este artigo se insere em campo do conhecimento raramente abordado por pesquisadores acadêmicos no Brasil,

*Bacharel em Ciências Militares, com ênfase em Comunicações, pela Academia Militar das Agulhas Negras. Capitão de Comunicações da reserva do Exército Brasileiro, instituição na qual permaneceu por cerca de 14 anos. Além da formação acadêmica e de cursos de especialização na área de Comunicações Militares, serviu por cerca de três anos e meio na $1^{a}$ Companhia de Comunicações de Selva, ManausAM, por cerca de um ano e meio no Centro Integrado de Guerra Eletrônica, BrasíliaDF, e por cerca de quatro anos na Companhia de Comando e Controle, Brasília-DF, organizações militares de Comunicações pertencentes ao Exército Brasileiro. Contato: rodrigoch80@ hotmail.com. 
possuindo, desta forma, papel pioneiro no sentido de contribuir para que temáticas jurídicas relacionadas à Defesa Nacional, em particular às Comunicações Militares, adentrem no plano de discussão da sociedade civil.

Palavras-chave: Ministério da Defesa, comunicações militares, integração, regulação, Brasil.

\begin{abstract}
Purpose - The purpose of this article is to introduce the reader to the technical and political context whereupon are inserted the Military Communications in Brazil, evidencing the regulatory and integrative role currently played by the Ministry of Defense.

Methodology/approach/design - This research makes predominant use of descriptive and comparative techniques, in order to inform the reader on the subject highlighted.

Findings - The article concludes with the need for rationalization and unification of national policy for Military Communications, as determinant for the effective integration of the Armed Forces in joint operations.

Practical implications - The article highlights the benefits that standardization of technical requirements by the Ministry of Defense may bring in terms of reducing the cost of purchasing and maintaining equipment and military communications systems, by way of enhancing economies of scale, effectiveness and operational efficiency in the joint operations of the Armed Forces.

Originality/value - This article addresses a branch of knowledge rarely assessed by academic researchers in Brazil having thus pioneering role in contributing to issues related to National Defense as Military Communications are discussed by civil society.
\end{abstract}

Keywords: Ministry of Defense, military communications, integration, regulation, Brazil.

\title{
1. Introdução
}

As Comunicações Militares no Brasil se desenvolveram, historicamente, de forma isolada no âmbito de cada componente das Forças Armadas 
brasileiras - Exército Brasileiro, Marinha do Brasil e Força Aérea Brasileira —, visando atender, de forma não integrada sistemicamente, as estruturas organizacionais particulares, com enfoque institucional individualizado de suprimento das necessidades estratégicas, operacionais e táticas de cada Força singular.

Esta política não integrada $^{1}$ era implementada e estimulada, aparentemente, pelo fato de cada Força singular possuir um Ministro de Estado autônomo, situação que perdurou até a criação do Ministério da Defesa, em 10 de junho de 1999, e que ocasionava, constantemente, a incompatibilidade técnica entre os sistemas que compunham os meios de comunicações de cada Força singular, e consequente incomunicabilidade entre os inúmeros equipamentos e sistemas de comunicações nas operações conjuntas $^{2}$, fator crucial para a perda de eficiência e de eficácia operacional do sistema de Comando e Controle 3 na atuação em conjunto das Forças Armadas.

“(...) Os conflitos atuais tendem a ser limitados, não declarados, convencionais ou não, e de duração imprevisível. As ameaças são fluidas, difusas e também imprevisíveis. Tudo isso exige que o preparo das Forças Armadas seja baseado em capacidades, significando isto

${ }^{1}$ Deve-se entender como política não integrada a falta de unificação normativa e de compatibilidade técnica entre os sistemas de comunicações estabelecidos, que possibilitasse a integração e a intercomunicação entre os diversos sistemas de comunicações das Forças Armadas.

${ }^{2}$ As Operações Conjuntas caracterizam-se pelo emprego de meios ponderáveis de mais de uma Força Singular, sob comando único (Ministério da Defesa, MD30-M01, vol. 1, p. 37, 2011).

${ }^{3}$ Comando e Controle significa a ciência e arte que trata do funcionamento de uma cadeia de comando e, nessa concepção, envolve, basicamente, três componentes: a) a autoridade legitimamente investida apoiada por uma organização da qual emanam as decisões que materializam o exercício do comando e para onde fluem as informações necessárias ao exercício do controle; b) a sistemática de um processo decisório que permite a formulação de ordens, estabelece o fluxo de informações e assegura mecanismos destinados à garantia do cumprimento pleno das ordens; e c) a estrutura, incluindo pessoal, equipamento, doutrina e tecnologia necessários para a autoridade acompanhar o desenvolvimento das operações (Ministério da Defesa, MD31-D-03, p. 13, 2006).

Revista de Direito, Estado e Telecomunicações, v. 6, n. 1, p. 87-108 (2014) 
dispor de forças militares capazes de atuar de forma conjunta, dotadas de flexibilidade, versatilidade e mobilidade.

As operações militares de grande envergadura exigem o emprego ponderável de elementos pertencentes a mais de uma Força Armada. Para tal, as Forças Singulares devem somar esforços, compatibilizar procedimentos e integrar as ações, de forma a se obter maior eficiência na execução das Operações Conjuntas.

O planejamento de uma Operação Conjunta, embora semelhante ao de qualquer outra operação, diferencia-se pela heterogeneidade dos processos de emprego e pelas peculiaridades técnico-profissionais das Forças Componentes. Avulta, assim, a importância da coordenação e da integração das ações planejadas.

Os planejamentos das Operações Conjuntas podem ser conduzidos nos níveis estratégico, operacional e tático e devem considerar a crescente complexidade dos meios das Forças Armadas, exigindo, mais do que nunca, maior integração das estruturas de comando e controle, de inteligência e de logística.

O Comandante Operacional, na condução de campanhas e operações, sincroniza as ações navais, aéreas e terrestres para alcançar os objetivos estratégicos e operacionais, em harmonia com os esforços políticos, diplomáticos e econômicos. A meta é obter a eficácia por intermédio da sinergia das Forças Componentes. (...)" (Ministério da Defesa, MD30-M-01, p. 13, 2011).

Ressalta-se que, atualmente, esta realidade ainda não se encontra plenamente superada, porém já existem significativos avanços políticos e técnicos neste sentido, decorrentes do surgimento do Ministério da Defesa como órgão central responsável pela padronização dos requisitos técnicos de equipamentos e de sistemas de comunicações militares e pela normatização das práticas operacionais, da exploração e do emprego das comunicações militares nas operações conjuntas.

\section{As comunicações militares como espécie do gênero comunicações}

As comunicações como gênero, em acepção ampla, podem ser entendidas como o conjunto instrumental de atos, procedimentos, 
tecnologias, protocolos e codificações que permitam o tráfego de informações, por meio do trânsito de mensagens entre emissor e receptor, em determinado canal de comunicação.

Desta forma, os processos de comunicações englobam quaisquer meios ou métodos visuais, sonoros, linguísticos ou tecnológicos que permitam a transmissão de informações, como, por exemplo, a linguagem verbal, os painéis de propaganda visual, a internet, a difusão de som e imagem por meio do uso de radiofrequência modulada, entre outros.

Neste ponto, aflora a necessária distinção conceitual entre telecomunicações e comunicações, cujos significados, não raro, são confundidos. Conforme retro evidenciado, o primeiro conceito constitui, na verdade, mera espécie do segundo, caraterizada, simplesmente, pelo processo físico de tráfego de informações pelo canal de comunicação. ${ }^{4}$

O conceito legal consta da Lei Geral das Telecomunicações brasileira:

Art. 60 (...)

Lei 9.472 , de 16 de julho de 1997

$\S 1^{\circ}$ Telecomunicação é a transmissão, emissão ou recepção, por

fio, radioeletricidade, meio ópticos ou qualquer outro processo eletromagnético, de símbolos, caracteres, sinais, escritos, imagens, sons ou informações de qualquer natureza."

As comunicações militares, por sua vez, se diferenciam do gênero comunicações, basicamente, por sua aplicação às forças militares, haja vista que, essencialmente, também se utilizam de meios eficazes que garantam a transmissão de informações entre emissor e transmissor, porém este processo é quase sempre materializado por meios que garantam o tráfego seguro de informações, pelo uso de protocolos exclusivos e/ou de algoritmos de criptografia.

No planejamento dos sistemas de comunicações militares de campanha, a depender do nível organizacional atendido, são previstos desde meros mensageiros humanos, a exemplo do mítico soldado ateniense Feidípedes,

${ }^{4}$ Pode-se encontrar maior aprofundamento técnico-conceitual, que permite melhor compreensão desta distinção, nos tópicos Telecomunicações e Serviços de Telecomunicações e Elementos conceituais das telecomunicações em Aranha (2013, 161-166). 
que teria corrido cerca de 40 quilômetros entre a planície de Marathónas e Atenas para avisar sobre a vitória do exército de Atenas contra os Persas, no ano de 490 a.C., painéis de cor, como os utilizados para balizar a aterrisagem de helicópteros em campo aberto ou para identificar tropas amigas no terreno, meios alternativos, como sinais de fumaça ou de luz com o uso de espelhos pelo dia ou de lâmpadas pela noite, até o uso de complexos sistemas de comunicações via satélite.

\section{As comunicações militares como instrumento do sistema de Comando e Controle no âmbito das Forças Armadas}

As comunicações militares constituem instrumento primordial integrante do sistema de Comando e Controle das operações militares ${ }^{5}$ e, constantemente, estão submetidas ao contexto praticamente infindável de variantes operacionais que configuram o teatro de operações em que atua determinada força militar, tais como, a topografia do terreno, a vegetação predominante, as condições meteorológicas, a altitude e a longitude do local, dentre outros fatores.

Diferentemente do uso das comunicações pela sociedade civil, em que, frequentemente, o ambiente operacional é estável ou passível de previsibilidade $^{6}$, nas operações militares, normalmente, a instabilidade é a regra. $^{7}$

${ }^{5}$ Devido à interdependência sistêmica, boa parte da doutrina militar mundial costuma unificar em sigla única as atividades de Comando e Controle, de Comunicações e de Inteligência: $\mathrm{C}^{3} \mathrm{I}$ - Command, Control, Communications and Intelligence. Conferir: COAKLEY, Thomas P. Intelligence. The Eyes of $C^{3} I$. In: $C^{3} I$ : Issues of Command and Control, 1990.

${ }^{6}$ Pode-se citar, como exemplo, uma rede de telefonia móvel de determinada concessionária privada de telefonia celular, em que uma vez realizados os estudos técnicos necessários sobre as condicionantes climáticas e topográficas, e subsequente dimensionamento e definição do sistema a ser instalado, as antenas (Estações Rádio Base - ERB) são fixadas em determinados pontos e, raramente, suas posições serão modificadas no futuro.

${ }^{7}$ Como exemplo, o uso de rádio comunicadores, em faixa de frequência HF, por tropas que se desloquem pelo terreno, requer constante mudança no direcionamento e na dimensão da antena utilizada, bem como constante recálculo da frequência a ser 
$\mathrm{Na}$ seara da hierarquia militar, predomina o exercício contínuo do princípio da unidade de comando ${ }^{8}$, que deriva da necessidade óbvia de que as decisões sejam oportunas e centralizadas, já que em situações extraordinárias, normalmente configuradas nas operações militares, não é plausível a tomada de decisões colegiadas, por mera premissa de tempo, tendo em vista que diante de determinadas situações, não raramente a decisão deve ser tomada, acertadamente, dentro de poucos segundos.

$\mathrm{O}$ exercício do comando em operações militares pelas autoridades competentes é quase sempre dificultado pela natural dispersão das frações militares pelos ambientes em que operam, em razão diretamente proporcional à dimensão da área em que se atua e ao avanço na cadeia hierárquica, pelo simples fato de que quanto maior for a precedência hierárquica de determinada autoridade militar, maior será o número de frações militares a ela subordinadas.

Desta forma, a eficácia e a eficiência do Sistema de Comando $e$ Controle, que atende determinada operação militar, dependem diretamente do desempenho dos integrantes dos quadros de comunicações militares e da qualidade técnica dos equipamentos utilizados, que permitem que as informações atinentes à operação transitem adequadamente pela cadeia de comando, de forma a permitir que a tomada de decisão seja oportuna.

\section{O uso das comunicações no âmbito de cada Força singular}

No tocante às particularidades de cada Força singular, quanto ao uso das comunicações, o senso comum leva a crer que cada Força singular possui

utilizada, conforme o horário do dia, tendo em vista a constante mudança ionização da camada ionosférica, que influenciam diretamente o fenômeno da refração ionosférica utilizado com primazia na propagação das ondas eletromagnéticas, na faixa de HF.

${ }^{8}$ UNIDADE DE COMANDO - 1 . Singularidade funcional do comandante em qualquer organização militar, de menor ou de maior nível, significando que a autoridade de direção e controle da força é atribuída e exercida por uma só pessoa e que, reciprocamente, qualquer militar ou comandante está subordinado a um único chefe superior. 2. O mesmo que PRINCÍPIO DA UNIDADE DE COMANDO (Ministério da Defesa, MD35-G-01, p. 260, 2007). 
necessidades operacionais definidas, única e exclusivamente, pela atuação predominante de cada uma delas.

Neste diapasão, as necessidades operacionais de comunicações pelo Exército Brasileiro estariam erroneamente associadas, exclusivamente, à necessidade do exercício do comando e controle de tropas que se deslocam pelo terreno. Enquanto, a Marinha do Brasil estaria associada, unicamente, as comunicações marítimas, e a Força Aérea Brasileira às comunicações aeronáuticas.

Ocorre todavia que, buscando atingir plenamente a capacidade de atuação independente, mutatis mutandis, as Forças singulares possuem tropas especializadas não apenas na sua principal atividade fim.

Neste sentido, o Exército Brasileiro possui quadros próprios de aviação militar, de artilharia antiaérea e de transporte fluvial de tropas, neste último caso, especialmente na região amazônica. A Marinha do Brasil, por sua vez, possui quadros próprios de aviação militar e de fuzileiros navais, assim como, a Força Aérea Brasileira possui quadros próprios de tropas de infantaria.

Pelo exposto, torna-se notório que, não obstante o predomínio de atividades associadas à área fim principal, o uso dos meios de comunicações pelas Forças Singulares possuem inúmeros pontos de confluência técnica e procedimental.

Afora o acima evidenciado, nas operações conjuntas das Forças Armadas, que normalmente se desdobram por grandes extensões territoriais, existe a necessidade primordial de integração técnica ${ }^{9}$ e de uniformização de procedimentos ${ }^{10}$ entre as comunicações das Forças singulares, integração

${ }^{9}$ Deve-se entender como integração técnica a capacidade de intercomunicação entre os sistemas de comunicações das Forças singulares, por meio da adoção de protocolos de segurança da informação compatíveis e de equipamentos com tecnologias similares.

${ }^{10}$ Deve-se entender como uniformização de procedimentos a padronização operacional de procedimentos humanos, tais como, os diálogos codificados utilizados nas transmissões de mensagens por voz, via equipamentos de rádio ou de telefonia. 
que constitui, por si só, fator decisivo para o sucesso do sistema de Comando e Controle.

Nas operações conjuntas, torna-se essencial a sincronização das ações entre as Forças singulares, permitida, quase que exclusivamente, pela ação das comunicações militares.

É o que ocorre no lançamento aéreo de suprimentos para equipes em solo, na coordenação de fogos de defesa antiaérea, no desembarque de tropas na costa marítima, na escolta aérea de comboios logísticos terrestres, dentre inúmeros outros exemplos.

É possível afirmar que, em praticamente todos os casos de fogo amigo ${ }^{11}$, entre forças militares em campanha, existem falhas identificáveis no processo de comunicação e/ou de autenticação entre os componentes envolvidos.

\section{A problemática da integração técnica entre os sistemas de comunicações das Forças singulares nas operações conjuntas}

O entendimento da gênese da problemática que prejudica a integração técnica entre os sistemas de comunicações das forças singulares, requer, necessariamente, além da compreensão do componente político que deriva da forma como se estruturou, historicamente, a administração militar no Brasil - ainda hoje praticamente autônoma na seara de cada força singular -, a compreensão da complexidade técnica e operacional que condiciona o uso dos meios de comunicações por cada tipo de tropa especializada, que compõem as forças singulares.

A comunicação naval e a aérea, por exemplo, requerem sistemas que permitam superar grandes distâncias, logo, normalmente, se valem de médias e altas frequências e equipamentos com grande potência de transmissão, enquanto que a comunicação submarina requer o uso de frequências extremamente baixas, capazes de se propagarem pelo meio líquido, em grandes distâncias.

${ }^{11}$ Deve-se entender como fogo amigo o ataque errôneo realizado por determinada fração militar contra outra fração militar aliada.

Revista de Direito, Estado e Telecomunicações, v. 6, n. 1, p. 87-108 (2014)

DOI: https://doi.org/10.26512/lstr.v6i1.21553 
Por sua vez, pequenas frações militares constituídas por um grupo reduzido de homens, deslocando-se pelo terreno em missões isoladas - aqui surgem outras condicionantes técnicas, a depender das características topográficas, climáticas e da vegetação que constituem o local de atuação costumam utilizar equipamentos de peso reduzido, o que limita a potência de transmissão, reduzindo, assim, o alcance dos seus meios de comunicações.

Por outro lado, grandes Comandos estratégicos costumam possuir adequada infraestrutura que permite a instalação de quaisquer meios de comunicações, de modo a facilitar a recepção e transmissão de mensagens à todos os demais componentes subordinados.

Logo, torna-se evidente que, a depender do nível organizacional atendido e do contexto operacional, as forças militares necessitam utilizar diferentes faixas do espectro eletromagnético e diferentes protocolos de recepção, transmissão e codificação das mensagens, bem como de processos de criptografia diversos.

Assim, fica evidente a complexidade técnica que permeia a necessidade de integração entre os meios de comunicações das forças singulares.

Não obstante tal fator, cada força singular, em dias atuais, praticamente ainda possui política particular de licitações para a aquisição e para a logística de manutenção dos seus sistemas e equipamentos de comunicações militares.

Esta situação contribui para a adoção, praticamente indiscriminada, de requisitos técnicos não uniformes na aquisição de sistemas e equipamentos, o que dificulta o alcance da desejada capacidade de intercomunicação entre os meios de comunicações das forças singulares e a adoção de uma política racional de logística integrada - em especial, de aquisição e de manutenção -, com evidentes ganhos em economias de escala e redução de custos, subsequente. 


\section{A vulnerabilidade das comunicações estratégicas no Brasil}

O Estado brasileiro não possui atualmente um sistema nacional integrado de comunicações estratégicas ${ }^{12}$ dotado, adequadamente, de meios de segurança da informação, que sejam eficazes no combate às previsíveis ações dos serviços de inteligência de outros Estados contra o país.

Desta forma, o Brasil torna-se alvo praticamente desprotegido de interesses de outros Estados, não apenas na seara militar, mas especialmente na seara da economia e da política internacional.

Apesar da recente institucionalização do Governo Federal no tocante aos assuntos de Defesa Nacional e de Inteligência Estratégica, com a criação do Gabinete de Segurança Institucional (GSI) - que substituiu a Casa Militar -, do Ministério da Defesa e da Agência Brasileira de Inteligência (ABIN), em 1999, verifica-se, ainda, uma verdadeira cisão institucional no tocante aos assuntos de Segurança Nacional.

Aparentemente, o Estado brasileiro manteve por muito tempo uma cultura institucional de reserva de quaisquer assuntos relevantes relacionados à Defesa Nacional apenas às autoridades militares das Forças Armadas.

Não obstante os recentes esforços institucionais em sentido contrário, esta práxis ainda necessita ser superada.

Ao atuarem desta forma, a alta cúpula do Poder Executivo e do Poder Legislativo federal omitem-se em tratar tais assuntos como objetivos estratégicos do país. Esta realidade institucional não permite o adequado debate político pela sociedade civil sobre as decisões estratégicas voltadas à Defesa Nacional, e, ao mesmo tempo, não elencam tais assuntos na agenda política do Estado brasileiro.

$\mathrm{Na}$ seara da inteligência estratégica estatal, por exemplo, cada força singular que compõe as Forças Armadas brasileiras possui, ainda em tempos atuais, quadros institucionais próprios de inteligência que praticamente não

${ }^{12}$ Quanto às Comunicações de Estado, diferentemente dos níveis operacionais e táticos, no nível estratégico predomina o tráfego de informações diretamente relacionadas com o atendimento dos elevados interesses nacionais, em temáticas e contextos diversos, cujos objetivos e alternativas executórias são formulados e definidos pela alta cúpula política e administrativa do Estado. 
se comunicam com os quadros da Agência Brasileira de Inteligência, que ainda se encontra em plena fase inicial de amadurecimento institucional. ${ }^{13}$

Em razão de existir uma relação praticamente simbiótica entre as atividades de inteligência e de comunicações estratégicas (COAKLEY 1990, 277), torna-se evidente que o contexto apresentado colabora para o tímido desenvolvimento de um adequado sistema nacional de comunicações estratégicas, verdadeiramente unificado e constituído por profissionais especializados e sistemas de comunicações e de segurança da informação à altura dos interesses nacionais.

Corroborando negativamente com este quadro, o Sistema Brasileiro de Comunicação Militar por Satélite - SISCOMIS -, por onde trafegam boa parte dos dados e informações estratégicas das Forças Armadas brasileiras, atualmente, não possui soberania assegurada, pois os satélites que o compõem pertencem a empresa privada Star One S.A. (Figura 1), uma subsidiária integral da Embratel. ${ }^{14}$

${ }^{13}$ Ressalta-se que, atualmente, o Brasil é um dos raros países do mundo que recrutam os seus agentes do Serviço de Inteligência por meio de concurso público, constituído, basicamente, por meio de provas cognitivas. Enquanto, a quase totalidade das nações fazem este recrutamento baseado, predominantemente, no perfil psicológico e no histórico profissional dos candidatos, incluídas suas capacidades cognitivas, adequados ao tipo de atividade desenvolvida.

${ }^{14}$ Privatizada em 1998, transferindo, inclusive, o controle dos canais de satélite de uso exclusivo das Forças Armadas para os agentes privados vencedores da oferta pública. Atualmente, é controlada pela Telmex, uma empresa privada mexicana de telecomunicações. 


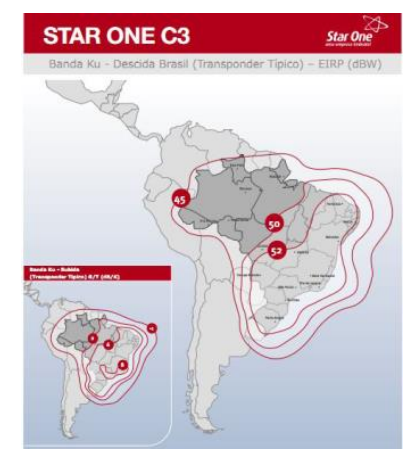

Figura 1 - Cobertura do satélite Star One C3

Por meio de contrato administrativo firmado entre o Ministério da Defesa e a empresa Star One S.A., as Forças Armadas brasileiras fazem uso de alguns canais da Banda $X$ (faixa de frequência de uso exclusivo das Forças Armadas), disponibilizados pelos satélites $\mathrm{C} 1$ e $\mathrm{C} 2$ e de alguns canais da Banda $\mathrm{Ku}$ (faixa de frequência de uso comercial), disponibilizados pelo satélite C3, ambos de propriedade da Star One S.A. ${ }^{15}$

\section{A importância do surgimento do Ministério da Defesa como órgão regulador e orientador da política de integração das comunicações militares no Brasil}

Apesar de não se tratar de um setor aberto à exploração econômica privada, pelo contrário, caracterizando-se como serviço público indelegável, que consta no rol das competências constitucionais exclusivas da União (Constituição Federal, art. 21, III), as comunicações militares, vistas sob enfoque de serviço público destinado a subsidiar a defesa nacional, encontra na doutrina que delimita e define o Estado Regulador amparo para o seu

${ }^{15}$ O Ministério da Defesa pagou pelo uso destes canais, somente em 2013, o total de $\mathrm{R} \$ 28.858 .054,86$ (vinte e oito milhões e oitocentos e cinquenta e oito mil e cinquenta e quatro reais e oitenta e seis centavos), até consulta realizada em 15 de dezembro de 2013 no Portal da Transparência do Governo Federal, disponível em:

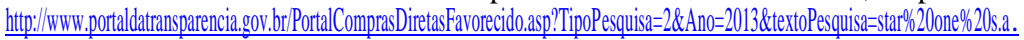


provimento estatal direto, constituindo-se em forma de regulação operacional centralizada. ${ }^{16}$

Para compreendermos o papel regulador exercido pelo Ministério da Defesa quanto às comunicações militares, torna-se importante, neste momento, o conceito de regulação.

"A regulação é um fenômeno mais abrangente de interferência estatal na atividade econômica em sentido amplo, envolvendo os serviços públicos e as atividades econômicas em sentido estrito. (...) A regulação, portanto, enquanto regime jurídico regulatório, apresenta-se como um conjunto de disposições normativas e administrativas caracterizadas por seu caráter conjuntural de influência ou controle sobre 0 ambiente regulado mediante batimento entre os resultados esperados $\mathrm{e}$ resultados efetivamente alcançados. (...) 0 regime jurídico regulatório transparece, portanto, o conjunto de produções não só normativas, mas administrativas de diuturna reconfiguração do ambiente regulado, como também do formato estatal de ataque aos problemas nele detectados, entendida a indispensabilidade de atuação estatal no que se refere à preservação dos princípios do serviço público, mediante políticas regulatórias ínsitas aos princípios jurídicos inscritos na ideologia constitucionalmente adotada. (...) A regulação, em síntese, é a presença de regras e atuação administrativa (law and governament) de caráter conjuntural pautadas no pressuposto de diuturna reconfiguração das normas de conduta e dos atos administrativos pertinentes para a finalidade de redirecionamento constante do comportamento das atividades submetidas a escrutínio, tendo-se por norte orientador parâmetros regulatórios definidos a partir dos enunciados de atos normativos e administrativos de garantia dos direitos fundamentais." (Aranha 2013, 84-89)

Neste sentido, a criação do Ministério da Defesa (MD), em 10 de junho de 1999, caracterizou o marco inicial da centralização política e administrativa das decisões de conteúdo programático que regulam as

${ }^{16}$ Vide as formas de regulação e os efeitos das opções regulatórias no livro intitulado Manual do Direito Regulatório, 2013, Márcio Iorio Aranha, p. 63-67. 
atividades desenvolvidas pelas Forças Armadas. Tal mudança institucional teve papel fundamental para as comunicações militares no Brasil.

O MD possui como missão ${ }^{17}$ : "coordenar o esforço integrado de defesa, visando contribuir para a garantia da soberania, dos poderes constitucionais, da lei e da ordem, do patrimônio nacional, a salvaguarda dos interesses nacionais e o incremento da inserção do Brasil no cenário internacional."

Dentre as competências do MD, elencadas pelo Decreto 7.974 , de $1^{\circ}$ de abril de 2013, que aprovou sua estrutura regimental, as seguintes se relacionam diretamente ou indiretamente às comunicações militares:

Art. $1^{\circ} 0$ Ministério da Defesa tem como área de competência os seguintes assuntos:

I - política de defesa nacional, estratégia nacional de defesa e elaboracão do Livro Branco de Defesa Nacional;

II - políticas e estratégias setoriais de defesa e militares;

III - doutrina, planejamento, organização, preparo e emprego conjunto e singular das Forças Armadas;

IV - projetos especiais de interesse da defesa nacional;

$\mathrm{V}$ - inteligência estratégica e operacional no interesse da defesa;

VI - operações militares das Forças Armadas;

VII - relacionamento internacional de defesa;

VIII - orçamento de defesa;

IX - legislação de defesa e militar; (...)

XII - política de ciência, tecnologia e inovação de defesa; (...)

$\mathrm{XV}$ - política nacional:

a) de exportação de produtos de defesa e fomento às atividades de pesquisa e desenvolvimento, produção e exportação em áreas de interesse da defesa e controle da exportação de produtos de defesa;

b) de indústria de defesa; e

c) de inteligência de defesa; (...)

XVII - logística de defesa; (...)

XX - constituição, organização, efetivos, adestramento e aprestamento das forças navais, terrestres e aéreas;

XXI - política marítima nacional;

XXII - segurança da navegação aérea e do tráfego aquaviário e salvaguarda da vida humana no mar; (...)

XXIV - políica militar aeronáutica e atuação na política aeroespacial nacional;

${ }^{17}$ Segundo informa a Portaria Normativa ${ }^{\circ}$ 1.797/MD, de 25 de novembro de 2010. Disponível em: http://www.defesa.gov.br/arquivos/File/2011/portaria normativa_179.pdf 
XXV - infraestrutura aeroespacial e aeronáutica; e

XXVI - operacionalização do Sistema de Proteção da Amazônia - SIPAM.

Este mesmo decreto também regulamentou a estrutura organizacional do Ministério da Defesa, com destaque quanto às comunicações militares, aos seguintes órgãos:

Art. $2^{\circ}$ O Ministério da Defesa tem a seguinte estrutura organizacional: (...)

II - órgãos de assessoramento:

a) Conselho Militar de Defesa; e

b) Estado-Maior Conjunto das Forças Armadas:

1. Gabinete do Estado-Maior Conjunto das Forças Armadas;

2. Chefia de Operações Conjuntas:

2.1. Subchefia de Comando e Controle;

2.2. Subchefia de Inteligência Operacional;

2.3. Subchefia de Operações; e

2.4. Subchefia de Logística Operacional;

3. Chefia de Assuntos Estratégicos: (...)

3.2. Subchefia de Inteligência Estratégica; e (...)

4. Chefia de Logística:

4.1. Subchefia de Integração Logística;

IV - órgãos específicos singulares:

a) Secretaria de Organização Institucional:

1. Departamento de Organização e Legislação;

2. Departamento de Planejamento, Orçamento e Finanças; (...)

4. Departamento de Tecnologia da Informação;

b) Secretaria de Produtos de Defesa:

1. Departamento de Produtos de Defesa;

2. Departamento de Ciência e Tecnologia Industrial; e (...)

VI - Forças Armadas:

a) Comando da Marinha;

b) Comando do Exército; e

c) Comando da Aeronáutica.

Quanto às comunicações militares, desde sua criação, o Ministério da Defesa vem editando atos normativos e manuais doutrinários ${ }^{18}$

${ }^{18}$ No tocante ao emprego das comunicações e ao Comando e Controle em operações conjuntas, destacam-se os seguintes manuais doutrinários: MD30-M-01 
especialmente destinados ao emprego conjunto das Forças Armadas e à adoção centralizada de requisitos técnicos operacionais.

Esta atuação vem contribuindo diretamente para a necessária mudança na cultura institucional das Forças singulares em planejarem suas políticas de comunicações militares de modo isolado.

Como exemplo nítido do acima exposto, no ano de 2009, o Exército Brasileiro criou a Companhia de Comando e Controle $\left(\mathrm{Cia} \mathrm{C}^{2}\right.$ ), organização militar de comunicações, sediada em Brasília, que possui como missão principal a de prestar o apoio complementar à instalação e manutenção dos sistemas de comunicações da Força Terrestre Componente, realizando a integração necessária nos níveis operacional e tático nas operações conjuntas das Forças Armadas.

Apesar das mudanças institucionais já verificadas, o esforço do Ministério da Defesa, neste sentido, tem-se mostrado ainda distante da situação ideal, pois ainda hoje não foi plenamente superada a grande autonomia que cada Força singular possui para definir livremente a sua política de aquisições e de logística de manutenção dos sistemas e equipamentos de comunicações estratégicas e operacionais de que fazem uso, isoladamente.

Tal fator ocasiona a evidente perda de economias de escala nos custos de aquisição e de manutenção de equipamentos, bem como a impossibilidade técnica de intercomunicação entre inúmeros sistemas e equipamentos de comunicações, de que dispõem o Exército Brasileiro, a Marinha do Brasil e a Força Aérea Brasileira, quando atuam conjuntamente.

É importante evidenciar, ainda, que os sistemas e equipamentos de comunicações militares, importados da indústria internacional ${ }^{19}$,

(DOUTRINA DE OPERAÇÕES CONJUNTAS, $1^{\circ}$ Volume, 2011); D31-D-03 (DOUTRINA MILITAR DE COMANDO E CONTROLE, 2006); MD31-P-01 (POLÍTICA PARA O SISTEMA MILITAR DE COMANDO E CONTROLE, 2001); MD33-M-03 (DOUTRINA BÁSICA DE COMANDO COMBINADO, 2001); dentre outros, incluídos aqueles de natureza reservada ou confidencial.

${ }^{19} \mathrm{O}$ Brasil, há muitos anos, é cliente assíduo da indústria internacional de comunicações militares, e, além do impacto negativo para a segurança nacional, o país costuma pagar valores altíssimos pela aquisição e manutenção de equipamentos, mesmo aqueles não componentes de sistemas complexos, por falta de uma indústria 
geralmente, são desenvolvidos em forma de sistemas integrados, comumente denominados como famílias, compostos por equipamentos compatíveis entre si, permitindo a intercomunicação, e costumam atender, simultaneamente, a necessidade dos diversos níveis hierárquicos que compõem a Cadeia de Comando de determinada Força militar, por meio da integração sistêmica entre os equipamentos que atendem aos diversos níveis da hierarquia de comando.

Logo, esta falta de coesão na política logística das Comunicações nas Forças Armadas, não favorece à aquisição de equipamentos individualmente inseridos em sistemas pensados como famílias de equipamentos, que facilitam a intercomunicação e a logística de manutenção e suprimento.

\section{A Estratégia Nacional de Defesa e as Comunicações Militares}

Segundo dispõe o Anexo ao Decreto 6.703, de 18 de dezembro de 2008, que aprovou a Estratégia Nacional de Defesa (END):

2. A Estratégia Nacional de Defesa organiza-se em torno de três eixos estruturantes.

0 primeiro eixo estruturante diz respeito a como as Forças Armadas devem-se organizar e orientar para melhor desempenharem sua destinação constitucional e suas atribuições na paz e na guerra. Enumeram-se diretrizes estratégicas relativas a cada uma das Forças e especifica-se a relação que deve prevalecer entre elas. (...)

0 segundo eixo estruturante refere-se à reorganização da indústria nacional de material de defesa, para assegurar que 0 atendimento das necessidades de equipamento das Forças Armadas apoie-se em tecnologias sob domínio nacional.

0 terceiro eixo estruturante versa sobre a composição dos efetivos das Forças Armadas e, consequentemente, sobre 0 futuro do Serviço Militar Obrigatório."

A END elenca como algumas das principais vulnerabilidades da atual estrutura de defesa do país: "a obsolescência da maioria dos equipamentos

nacional desenvolvida neste setor, que possui, inclusive, alto potencial de gerar dividendos oriundos de exportação para o país. 
das Forças Armadas; elevado grau de dependência em relação a produtos de defesa estrangeiros; e ausência de direção unificada para aquisições de produtos de defesa".

No intuito de reverter este quadro, a END determina, quando trata da estruturação das Forças Armadas:

- Quanto "a obsolescência da maioria dos equipamentos das Forças Armadas", além da necessidade de regularidade e continuidade na alocação dos recursos orçamentários de defesa, para incrementar os investimentos e garantir o custeio das Forças Armadas, o seguinte:

"O Ministério da Defesa proporá, em coordenação com os Ministérios das Relações Exteriores, da Fazenda, do Desenvolvimento, Indústria e Comércio Exterior, do Planejamento, Orçamento e Gestão, da Ciência e Tecnologia e com a Secretaria de Assuntos Estratégicos da Presidência da República, o estabelecimento de parcerias estratégicas com países que possam contribuir para 0 desenvolvimento de tecnologias de ponta de interesse para a defesa.

O Ministério da Defesa, ouvidos os Ministérios da Fazenda, do (...), deverá propor modificações na legislação referente ao regime jurídico e econômico especial para compras de produtos de defesa junto às empresas nacionais, com propostas de modificação da Lei no ${ }^{0}$.666, de junho de 1993." (grifos meus)

- Quanto ao "elevado grau de dependência em relação a produtos de defesa estrangeiros":

"O Ministério da Defesa, em articulação com os Ministérios (...), deverá propor modificações na legislação referente à tributação incidente sobre a indústria nacional de material de defesa, por meio da criação de regime jurídico especial que viabilize incentivos e desoneração tributária à iniciativa privada na fabricação de produto de defesa prioritário para as Forças Armadas e para a exportação.

O Ministério da Defesa, em articulação com os Ministérios (...) deverá propor modificações na legislação referente à linha de crédito especial, por intermédio do Banco Nacional de Desenvolvimento Econômico e Social (BNDES), para os produtos de defesa, similar às já concedidas para outras atividades.

O Ministério da Defesa, em articulação com os Ministérios (...) deverá propor modificações na legislação referente à 
viabilização, por parte do Ministério da Fazenda, de procedimentos de garantias para contratos de exportação de produto de defesa de grande vulto (...)". (grifos meus)

- Quanto a "ausência de direção unificada para aquisições de produtos de defesa":

"Para 0 atendimento eficaz das Hipóteses de Emprego, as Forças Armadas deverão estar organizadas e articuladas de maneira a facilitar a realização de operações conjuntas e singulares, adequadas às características peculiares das operações de cada uma das áreas estratégicas.

0 instrumento principal, por meio do qual as Forças desenvolverão sua flexibilidade tática e estratégica, será 0 trabalho coordenado entre as Forças, a fim de tirar proveito da dialética da concentração e desconcentração. Portanto, as Forças, como regra, definirão suas orientações operacionais em conjunto, privilegiando essa visão conjunta como forma de aprofundar suas capacidades e rejeitarão qualquer tentativa de definir orientação operacional isolada." (grifos meus)

\section{Conclusão}

É notório que o surgimento do Ministério da Defesa, em 1999, contribuiu sobremaneira para a implementação de objetivos estratégicos e programáticos orientados à racionalidade e à eficácia do emprego conjunto das Forças Armadas, à busca pela adoção de critérios técnicos uniformes entre as Forças Singulares e à coesão da política nacional das Comunicações Militares no Brasil, por meio do poder normativo que exerce.

Não obstante as evoluções institucionais até aqui consolidadas, é preciso que este avanço do MD continue - respeitando as particularidades operacionais de cada força singular e ciente de que a integração técnica plena de todos os sistemas e equipamentos de Comunicações Militares das Forças Armadas brasileiras constitui objetivo utópico - na busca pela padronização normativa dos requisitos técnicos a serem adotados pelos procedimentos licitatórios de aquisição de equipamentos de comunicações, conduzidos isoladamente por cada força singular.

Neste sentido, da racionalização oriunda de uma política integrada das comunicações militares, é possível, também, diminuir consideravelmente os 
custos, por meio de ganhos com economias de escala nos processos logísticos de aquisição, de manutenção e de suprimento dos meios de comunicações aos Comandos Militares das Forças Armadas, considerando a extensa dimensão territorial do país, por onde se estende toda a cadeia logística de comunicações militares.

\section{Bibliografia}

ARAGÃO, A. Princípio da legalidade e poder regulamentar no Estado contemporâneo. In: Boletim de Direito Administrativo, v. 5, p. 370-380, maio de 2002.

ARANHA, M. I. Manual de Direito Regulatório. Scotts Valley, CA: CreateSpace, 2013.

. Poder normativo do Executivo e teoria da regulação. In: Notícia do Direito Brasileiro, v. 9, p. 135-154, 2002.

BALDWIN, R.; CAVE, M.; LODGE, M. Understanding Regulation. $2^{\text {a }}$ ed., New York: Oxford University Press, 2012.

BAILEY, N. A.; FEDER, S. M. Operational Conflict Analysis. Washington, D.C.: Public Affairs Press, 1974.

CARLSON, A. B. Communications Systems. $2^{\text {a }}$ ed., New York: McGrawHill, 1975.

COAKLEY, T. P. C I I: Issues of Command and Control. Washington, D.C.: National Defense University, 1986.

FITTS, R. E. The Strategy of Electromagnetic Conflict. Los Altos, CA: Peninsula Publishing, 1980.

HAYKIN, S.; MOHER, M. Introdução aos sistemas de comunicação. $2^{\mathrm{a}}$ ed., São Paulo: Bookman, 2010.

LAWSON, J. S. The State Variables of a Command Control System. Proceedings for Qualitative Assessment of the Utility of Command and Control Systems. Office of the Secretary of Defense with the cooperation of the MITRE corporation. $\mathrm{C}^{3}$ Division. Washington, D.C.: National Defense University, 1980.

MARQUES NETO, Floriano de Azevedo. Direito das telecomunicações. In: SUNDFELD, Carlos Ari (org.). Direito administrativo econômico. São Paulo: Malheiros, 2000, p. 300-316. 
MELO, M. A. A política da ação regulatória: responsabilização, credibilidade e delegação. In: Revista Brasileira de Ciências Sociais, v. 16, n. 46, p. 55-68, junho de 2001.

OGUS, A. Regulation: Legal Form and Economic Theory. Portland: Hart, 2004.

ORR, G. E. Combat Operations C3I (Command, Control, Communications, and Intelligence): Fundamentals and Interactions. Air University, 1983.

\section{Normas e Manuais Doutrinários}

BRASIL. Lei Complementar n ${ }^{\circ}$ 97, de 9 de junho de 1999.

BRASIL. Decreto presidencial $n^{\circ} 7.974$, de $1^{\circ}$ de abril de 2013.

BRASIL. Decreto presidencial n ${ }^{\circ} 6.703$, de 18 de dezembro de 2008.

BRASIL. Portaria normativa MD $n^{\circ} 1.797$, de 25 de novembro de 2010 (Boletim do Ministério da Defesa)

MINISTÉRIO DA DEFESA. Manual MD30-M-01: Doutrina de Operações Conjuntas. $1^{a}$ Edição. Brasília: 2011. Disponível em: http://www.defesa.gov.br.

MINISTÉRIO DA DEFESA. Manual MD31-D-03: Doutrina Militar de Comando e Controle. $1^{a}$ Edição. Brasília: 2006. Disponível em: http://www.defesa.gov.br.

MINISTÉRIO DA DEFESA. Manual MD33-M-03: Doutrina básica de Comando Combinado $1^{\mathrm{a}}$ Edição. Brasília: 2001. Disponível em: http://www.defesa.gov.br.

ESCOLA SUPERIOR DE GUERRA. Operações Combinadas e Conjuntas. Rio de Janeiro: 1976. 